\title{
Assessing malingering and personality styles in dissociative identity disorder: A case report and literature review
}

\author{
Renzo C. Lanfranco ${ }^{1,2 *}$, Juan Carlos Martínez-Aguayo3 ${ }^{3}$ Marcelo Arancibia ${ }^{4}$
}

\begin{abstract}
${ }^{1}$ Department of Neuroscience, Karolinska Institutet, Stockholm, Sweden; ${ }^{2}$ Department of Psychology, University of Edinburgh, Edinburgh, United Kingdom; ${ }^{3}$ Department of Paediatrics, Faculty of Medicine, Universidad de Valparaíso, Viña del Mar, Chile; ${ }^{4}$ Interdisciplinary Centre for Health Studies (CIESAL), Universidad de Valparaíso, Viña del Mar, Chile.
\end{abstract}

*Corresponding author: Dr. Renzo Lanfranco, Department of Neuroscience, Karolinska Institutet, Biomedicum, D4, Solnavägen 9, 171 65, Stockholm, Sweden. Email: renzo.lanfranco@ki.se

\begin{abstract}
Dissociative identity disorder (DID), formerly known as multiple personality disorder, is characterised by two or more identities that control a patient's actions, each typically with a distinct personal history, self-awareness, and name. They are believed to be the result of trauma-related dissociative defence mechanisms. Substantial progress has been made to determine the psychometric signatures of dissociative identities. However, tools to discriminate genuine DID individuals from malingerers are still lacking. Here, we present the case of a DID patient who exhibited nine different identities. After clinically ruling out malingering and factitious behaviour, we assessed her primary identity and two alternate identities (a trauma identity and an avoidant identity) using the Millon Index of Personality Styles. We found three very distinct personality profiles, with evident differences between primary and alternate identities. The profiles had high consistency scores and moderate to low negative and positive impression scores, respectively, thus supporting the profile's validity for interpretation. This was supported by a malingering test as well. Future studies should employ personality inventories that go beyond psychopathological symptoms to describe the consistency and adaptation style of dissociative identities when assessing malingering.
\end{abstract}

Keywords: Dissociation; Dissociative Identity Disorder; Malingering; Assessment; Personality. 


\section{Introduction}

Dissociative identity disorder (DID), formerly known as multiple personality disorder, is characterised by two or more identities (or personalities) that control a person's behaviour and affects $1.1 \%$ to $1.5 \%$ of the population $(1,2)$. Typically, each identity has their own first-person perspective, self-awareness, personal history, self-image, and name $(3,4)$. These totally or partially compartmentalised identities are believed to be the product of dissociative defence mechanisms that unfold in the face of inescapable psychological trauma (5), most likely during childhood $(6,7)$. A common clinical and forensic concern is the detection of malingerers $(8,9)$, i.e. individuals who simulate DID symptoms for secondary gain. Some may even feign DID symptoms for no gain other than assuming the role of a patient, as in factitious disorders (10). While progress has been made finding sensitive tools to assessing malingering in DID, more tools are needed.

Here, we present the case of a patient diagnosed with DID who exhibited nine different alternate identities in the span of six months; three of her identities were assessed using standard malingering scales and the Millon Index of Personality Styles (MIPS), which helped us reach the consensus that her case was real while profiling three of her identities.

\subsection{Inter-identity amnesia}

One of the hallmarks of DID is interidentity amnesia (IIA), i.e. the inability of identities to recall events that were experienced by other identities. However, many studies have questioned the validity of IIA for assessment. Using explicit and implicit memory tests, researchers have found that the contents learned by one identity can influence the performance of another identity (11-14), including procedural (15), episodic $(16,17)$, and autobiographic memory contents $(18,19)$. This last finding is of crucial importance given that the trauma-centred theory of DID predicts that IIA should be the strongest with autobiographic contents $(20,21)$. Because some identities may be more focused on traumatic memories (trauma identities or Tls) while others avoid them (avoidant identities or Als), researchers thought that IIA could be specific to them. However, while Tls retrieve more trauma-related memories than other identities, they do not exhibit IIA (19,22). Therefore, memory assessments have not proven fruitful at discriminating real DID patients from malingerers.

\subsection{Personality assessments}

While studies using structured interviews and questionnaires have shown that simulators can convincingly feign DID symptoms $(23,24)$, studies employing the Minnesota Multiphasic Personality Inventory (MMPI/MMPI-2) have yielded more nuanced results. DID patients tend to elevate many clinical scales, e.g. Schizophrenia, Psychopathic Deviate, and Depression (24,25), alongside validity scales, thus oftentimes yielding invalid profiles. Importantly, the Infrequencypsychopathology scale (Fp), designed to detect malingering in severe patients, has shown sensitivity to discriminating genuine DID patients from simulators (25). More recent studies have found that while DID patients frequently endorse items related to dissociation, trauma, depression, fearfulness, family conflict, 
and self-destructiveness, simulators tend to endorse items more consistent with popular media portrayals of DID as paranoid, delusional, and antisocial (26). Therefore, MMPI/MMPI2 studies on commonly endorsed items show promise at discriminating simulators from genuine DID patients, but more research is needed.

The Personality Assessment Inventory (PAI) has also been studied with this purpose. DID patients often elevate Negative Impression (NIM); however, while this scale is the most sensitive one to dissociative symptoms (27), it may be partly due to its inability to discriminate exaggerated from dissociative symptoms (28). Malingering Index (MAL) and Rogers Discriminant Function (RDF) scales have also shown sensitivity to malingering, with RDF displaying higher sensitivity to malingering in DID patients (29). In summary, personality tests have shown sensitivity to malingering in DID, but future studies are needed to establish their specificity.

However, most psychometric studies assessing the validity of DID patients' symptoms have employed inventories that focus on personality traits. To our knowledge, no study to date has employed inventories that focus on personality styles, i.e. each personality dimension's polarity (e.g. introversion alongside extraversion). These may provide more comprehensive profiles, helping clinicians not only to assess DID cases' validity, but also to betterunderstand how DID identities are formed.

Next, we present the case of a DID patient who exhibited nine identities. To further assess the validity of her case, we first used standard scales to assess dissociative symptoms (Dissociative Experiences Scale II or DES-II) and malingering (Miller Forensic Assessment of Symptoms Test or M-FAST). Subsequently, we employed the MIPS, which contains validity scales of response consistency, positive impression, and negative impression. Furthermore, the MIPS assesses personality styles, thus describing the individual's personality more holistically, beyond psychopathology-inspired classifications. We assessed the primary identity and two alternate identities - a TI and an Al.

\section{Case study}

A 17-year-old patient (henceforth AV), female, at third year of secondary schooling (eleventh year of school education), with very good grade point average (GPA; 6.5 in a 1-7 scale) brought by her sister, consulted with a psychiatrist (JCM-A) claiming to suffer from nine multiple personalities, all female and of diverse ages and traits, during the past two years.

AV provided written consent as an adult (year 2021) for her case to be published; non-essential personal information was changed or omitted for identity protection.

\subsection{Family history}

AV lived with her parents and sister; they described living in harmony, having no relevant conflicts. AV maintained a close relationship with her sister (aged 28), feeling confidence and emotional dependency to her. AV did not have family history of psychiatric disorders. 


\subsection{Past medical history}

AV had a normal pregnancy history. She consulted with another psychiatrist due to the appearance of multiple identities two years before. However, the treatment was not concluded. When AV was asked for traumatic events, she pointed out that a man threatened her with a knife during a bus trip with the intention of touching her genital area two years before. She also referred that her best female friend, who erotically attracted her, had moved to Canada.

\subsection{Current medical history}

AV reported that her symptoms started two years before her medical appointment. The first episode took place early in 2011 during a family dinner at home - she suddenly ran away from the place. She referred:

The first time it happened while I was having tea with my parents and sister. I stood up, opened the door, and run away to the street. They stopped me, as I was told, because I can't remember, I began shouting violently: 'someone wants to kidnap me... I'm J..., a homeless person... a beggar without a family.' I couldn't recognise anyone. I was taken to the hospital.

The episodes gradually increased in frequency and duration, from two hours to a week, always with ad-integrum recovery. She could partially remember them, most of which occurred at any time, place, or circumstance and with no clear association to any stressor. As she described:
They are like an inner switch... I disappear. At first, I was able to remember something, like being in a movie, but I haven't been able to remember... since January [2013].

She described her experiences as egodystonic, annoying, and disturbing. AV exhibited fear and anguish against these "personality changes", asking actively for help.

During the first clinical interview (April 2013), AV looked according to her chronological age. She was fully aware with no signs of temporospatial disorientation or alterations in prosody or verbal expression. She did not show impairments or alterations in thinking structure or content such as delirious ideas, or sensory-perceptual alterations. No impairments in psychomotricity. She did not present symptoms that could suggest mood or personality disorders. She exhibited empathetic concern with no fantasy or exaggeration. It was not possible to find any secondary gain or manipulative objective. Her moral consciousness was adequate for her age and her reasoning functioned at hypothetico-deductive level. She was also able to project herself in time.

Despite defining herself as quiet, responsible, and shy with mental stability (primary identity), on some occasions she would adopt a sociable, reckless, and defensive alternate identity. AV exhibited no signs of social phobia or of any other anxiety disorder. When asked about her fears, she indicated losing people she loved or being far from them. She declared having a homosexual orientation with no gender dysphoria, which one year later evolved into a bisexual orientation with no gender dysphoria. Biochemical profile, 
electroencephalogram, and computed tomography showed no pathological signs.

Later in April 2013, after carefully ruling out other categorical disorders, the psychiatrist diagnosed her with DID; AV underwent outpatient therapy with $10 \mathrm{mg}$ of daily oral escitalopram, $40 \mathrm{mg}$ of daily oral ziprasidone, and was also referred to $\mathrm{RCL}$ for cognitive behavioural therapy (CBT) including medical hypnosis as adjuvant technique, based on its cognitive effects (30-34) and efficacy for dissociative disorders (35-37).

In May 2013, AV exhibited three alternate identities: "A..." for five days, "J..." for four days, and "Ú..." for one day. Her sister's departure from the house was hypothesised as a stressor, but AV reported not feeling emotionally affected by the event. Ziprasidone was stopped and the dosage of escitalopram was increased to $20 \mathrm{mg}$.

In June 2013, great improvement was observed: for two weeks AV only reported one dissociative episode (of 30 minutes of duration), after which she did not have dissociative episodes for a month and achieved full attendance at school. However, the next month she exhibited an identity switch while at school; this new identity was acknowledged as "E...". It occurred after a discussion with a friend, although AV did not describe the discussion stressful. AV consulted with the psychiatrist introducing herself as "E...", then she referred to her primary identity $(\mathrm{PI})$ in third person:

She $[\mathrm{PI}]$ is rude to us because she doesn't like us. She is shy and doesn't say anything when something bothers her, she doesn't defend herself and rarely gets angry. She maintains good relationships with her classmates and teacher. She likes her school and classmates, but she is lazy at home. She doesn't do the household chores.

After this, AV switched back to her PI. Two days later, she switched to an alternate identity called "AT...", self-inflicted wrist cuts, and took an overdose of psychoactive drugs while in an apparent altered state of consciousness. She was checked into a hospital. During the next two months, AV attended psychiatric and CBT sessions; she mentioned that she could not remember any of these events. Additionally, she described feeling a heterosexual attraction towards a man of her age.

Over the next two months, AV exhibited five alternate identities. Her school attendance was erratic. She got lost for one night, wandering the streets, possibly experiencing dissociative fugue. Furthermore, during this time she maintained an erotic relationship with a female friend. Her attendance to psychiatric and CBT sessions decreased in frequency.

Over the next four months, AV had no dissociative symptoms. However, the day before a psychiatric consult, she adopted the alternate identity of "X...". AV was enquired about X...'s date of origin, to which she replied:

I've been $X . .$. since always, I'm 16, I do whatever I want... I don't work or go to school, but today I appeared inside [PI] while at school because I live inside her, but I don't talk to her... She doesn't know me, and I don't care.

AV did not return to psychiatric consultations, but she kept attending CBT 
and hypnotherapy sessions until June 2014, during which her dissociative episodes decreased in frequency.

In 2021, RCL contacted AV to learn about her current state. AV was about to complete a university degree in speech therapy. She reported still experiencing dissociative episodes on occasion, however, they were much less frequent and disruptive than in the 2012-2014 period. See Figure 1 for a timeline of relevant events.

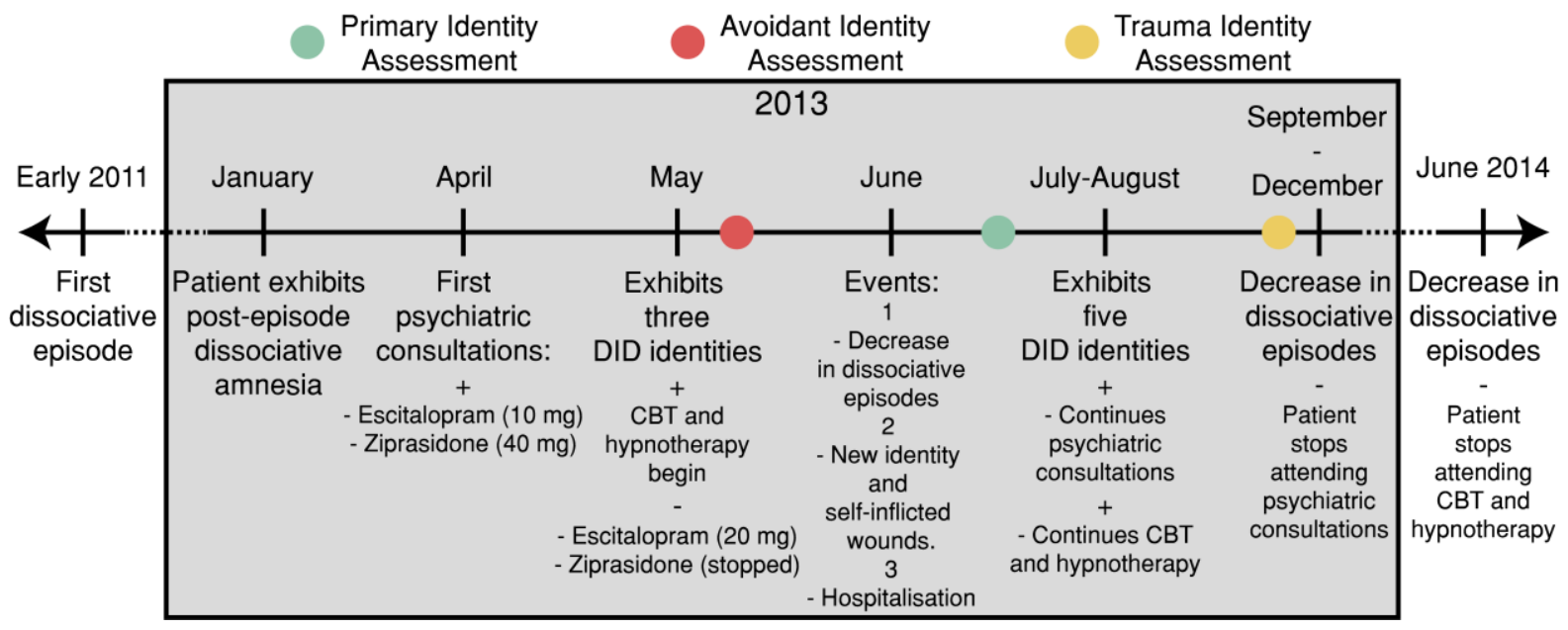

Figure 1. Timeline of relevant events for assessment and diagnosis

\subsection{Personality and malingering assessment}

The MIPS is a 180-item inventory that explores adaptation styles (38,39). Personality ailments are seen as specific maladaptive personality styles. The MIPS measures each polarity of a personality dimension individually (40), focusing on three areas: motivating styles, i.e. the emotional style of an individual at dealing with environmental demands; thinking styles, i.e. the cognitive style or thinking approach of an individual; and behaving styles, i.e. an individual's style to interact with others. Importantly, it includes three validity indices that estimate the extent to which examinees are trying to give a false impression of themselves (e.g. malingering): Positive impression, Negative impression, and Consistency. In Consistency, a score below 3 (out of 5) invalidates the profile (39).
We assessed three identities: an Al (introduced as "A..."), the PI ("host"), and a TI (introduced as "X..."). The identities were assessed at the beginning of CBT sessions, in this order, and with 1 or 2 months apart from each other. Al and TI were assessed in sessions where AV introduced herself as one of the names just mentioned, showing that an alternate identity was active. The nature of these alternate identities ( $\mathrm{Al}$ and $\mathrm{TI}$ ) was determined by RCL and JCM-A in clinical meetings.

\subsubsection{DES-II}

In each assessment session, AV was first asked to complete the DES-II, this to assess the severity of her symptoms. Her scores indicated high level of dissociation $(\mathrm{PI}=41 ; \mathrm{Al}=47 ; \mathrm{Tl}=49)$. 


\subsection{2. $M-F A S T$}

Next, AV was asked to answer a few questions. They were the 25 questions contained in the M-FAST for malingering assessment $(41,42)$. Both $\mathrm{Pl}$ and $\mathrm{Al}$ scored 3, whereas $\mathrm{TI}$ scored 4 . Since the cut-off score for suspecting malingering is 6 or higher, these results suggest absence of malingering.

\subsubsection{MIPS: Motivating styles}

Motivating styles assesses how individuals emotionally deal with their environment and its reinforcements. The identities show differences in all motivational styles, perhaps except for Pleasure-Enhancing (Figure 2). While both $\mathrm{PI}$ and $\mathrm{Al}$ showed a strong inclination to adopt a passive stance towards their life events, TI showed a weaker inclination in this area (PassivelyAccommodating). Additionally, the three identities showed very different profiles in Self-Indulging and Other-Nurturing; more specifically, while PI showed a low inclination for self-gratification and satisfying her own needs before others' (Self-Indulging), and a strong inclination to prioritizing others' needs, $\mathrm{Tl}$ exhibited the opposite trend, to an extreme. Remarkably, PI and TI showed opposite elevations in most scales.

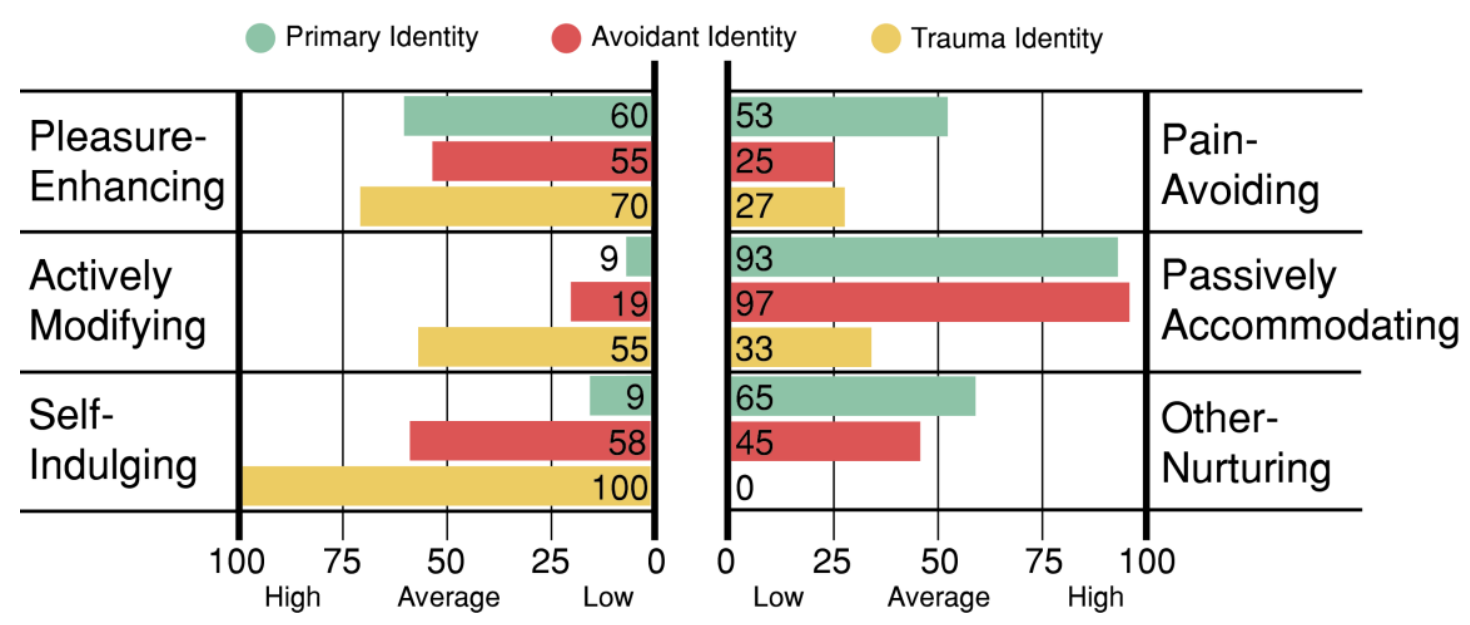

Figure 2. MIPS Motivating styles profiles for $\mathrm{PI}, \mathrm{Al}$, and a TI.

\subsubsection{MIPS: Thinking styles}

Thinking styles assesses individuals' modes of cognitive processing. The identities showed visible differences in all styles; the largest differences were observed between $\mathrm{Pl}$ and $\mathrm{TI}$ (Figure 3): while PI scored extremely low in Externally-Focused and extremely high in Internally-Focused, both alternate identities elevated those scales moderately. A similar contrast was observed in Realistic/Sensing and
Imaginative/Intuitive between $\mathrm{PI}$ and the alternate identities. Finally, while PI showed an inclination to make decisions based on her emotions and current circumstances (Feeling-Guided) and a relatively strong inclination to organization and planning (ConservationSeeking), the alternate identities showed opposite inclinations in those scales; apart from Al in Feeling-Guided. Overall, very distinctive personality profiles were observed between identities, with PI and 
TI showing opposite elevations in most scales.

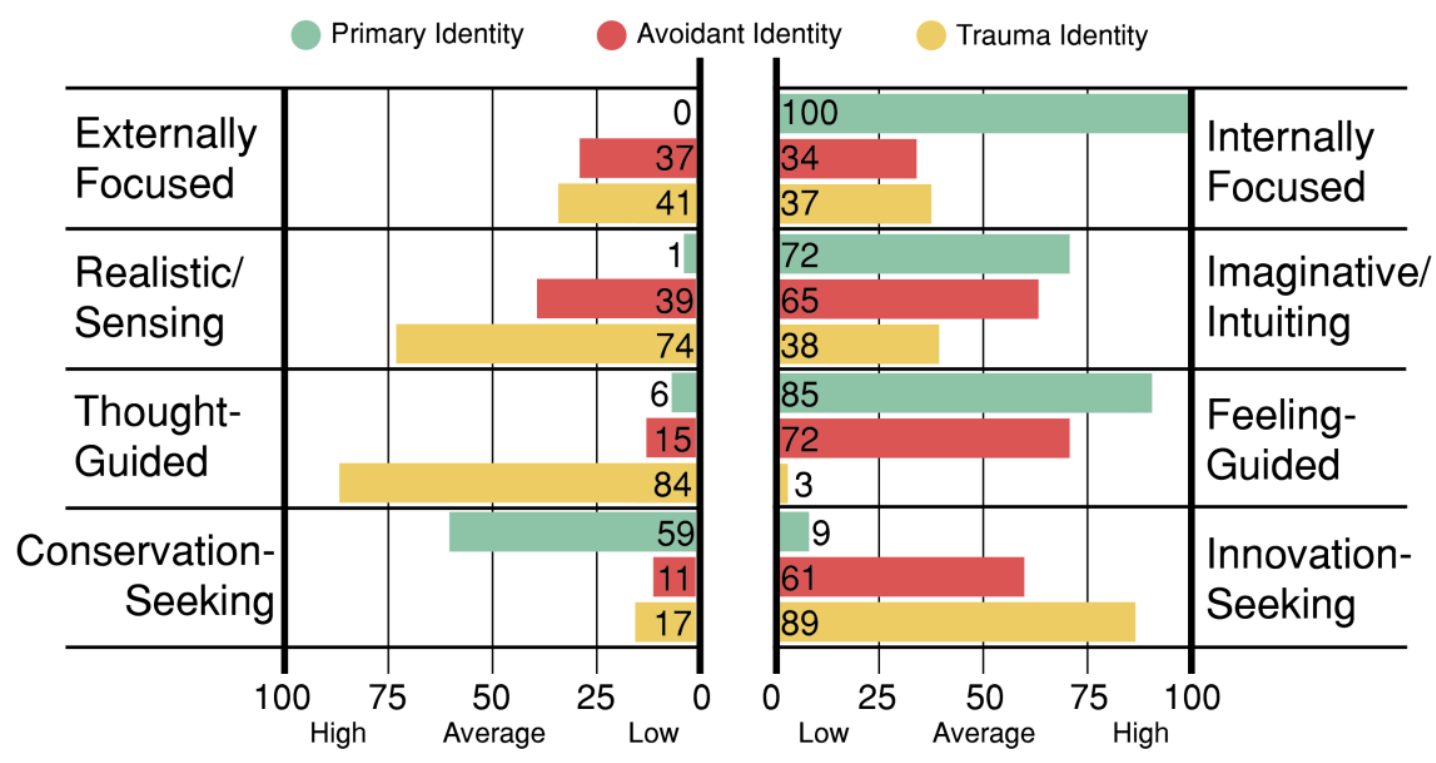

Figure 3. MIPS Thinking styles profiles for PI, an Al, and a TI.

\subsubsection{MIPS: Behaving styles}

Behaving styles assesses how individuals interact and develop social relationships. The identities showed visible differences (Figure 4): while PI showed inclination to social indifference (Asocial/Withdrawing), low interest in drawing attention from others (Gregarious/Outgoing), very high inclination to shyness and social awkwardness (Anxious/Hesitating), and low confidence (Confident/Asserting), TI showed the opposite pattern. The most extreme contrast is observed in Confident-Asserting: while PI scored very low, Al scored moderately, and TI scored very high. Furthermore, while $\mathrm{PI}$ and $\mathrm{Al}$ showed low tendency to agree with norms and a general attitude of nonconformity

(Unconventional/Dissenting), TI showed an extreme inclination in favour of this style. Finally, the three identities had pronounced differences in how socially dominant, aggressive, and energetic they behave (Dominant/Controlling), e.g. while PI scored very low here, TI scored extremely high. Thus, $\mathrm{PI}$ and $\mathrm{TI}$ showed opposite elevations in most scales again. 


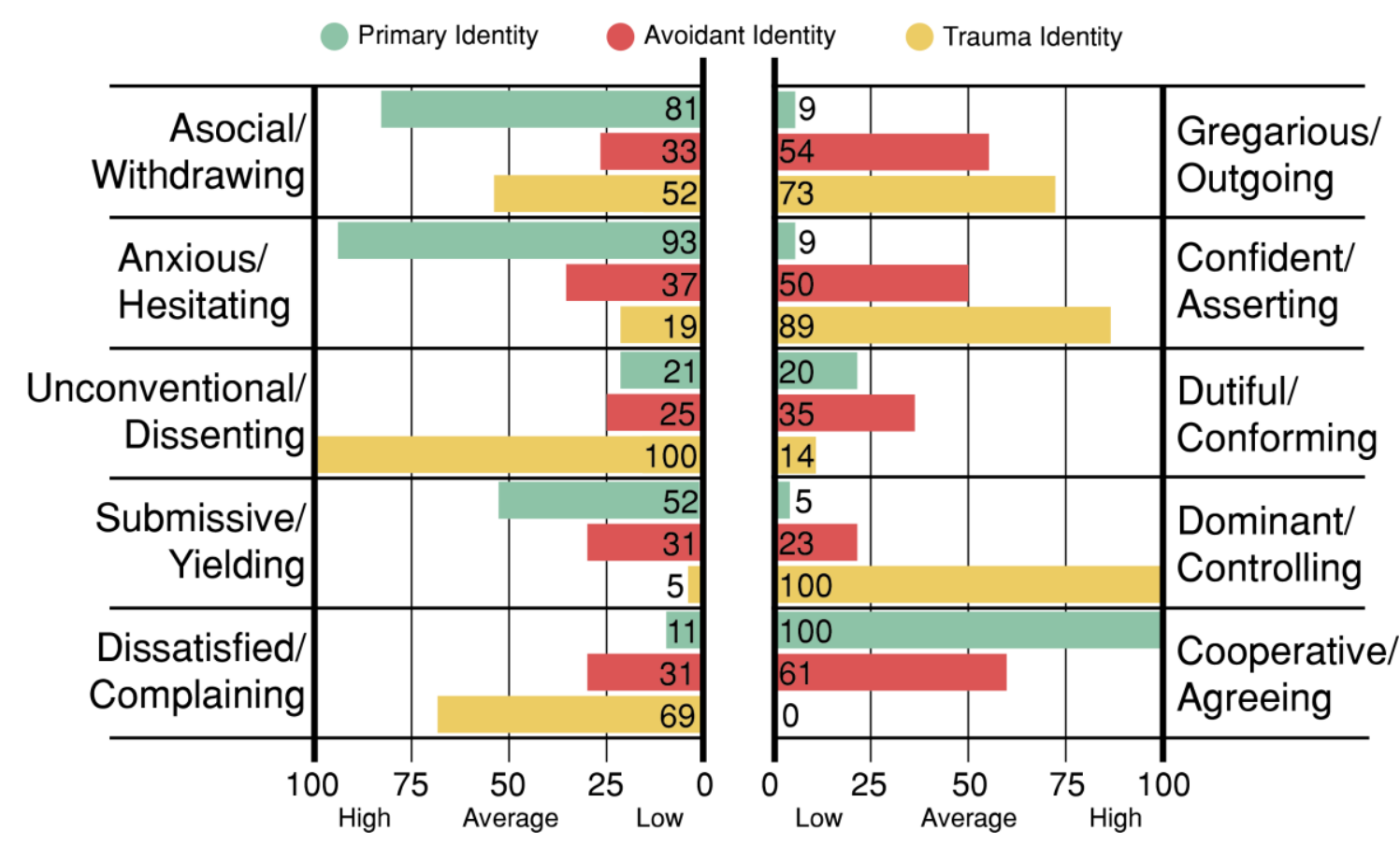

Figure 4. MIPS Behaving styles profiles for $\mathrm{PI}$, an $\mathrm{Al}$, and a $\mathrm{TI}$.

\subsubsection{MIPS: Validity scales}

The personality profiles had high consistency ( $\mathrm{Pl}=5 / 5 ; \quad \mathrm{Al}=4 / 5 ; \quad \mathrm{TI}=4 / 5)$. Additionally, while $\mathrm{PI}$ and $\mathrm{Al}$ scored moderately in Positive Impression ( $\mathrm{PI}=6$; $\mathrm{A} 1=7), \mathrm{TI}$ scored low ( $\mathrm{Tl}=2)$. Finally, $\mathrm{PI}$ scored in medium range for Negative Impression $(\mathrm{PI}=6)$. However, both alternate identities scored very low in this scale $(A I=2 ; T I=1)$. These observed scores suggest absence of malingering and are in line with the M-FAST results.

\section{Discussion}

DID is characterised by two or more identities that control a person's behaviour and self-awareness. DID is believed to be the product of traumainduced dissociations that typically occur during childhood (21), although many researchers have suggested that DID may be partially due to social learning, media influence, and cultural expectations $(43,44)$. How can clinicians discriminate genuine DID individuals from those who simulate $(25,45)$ ?

Studies employing personality inventories have made progress determining what scales are mor sensitivity to DID and malingering, but more studies are required to determine their specificity and new tools are constantly sought to capture more comprehensive pictures of DID while also assessing malingering.

We have presented the case of a DID patient who exhibited nine identities within six months, with no signs of primary or secondary gain from DID diagnosis. Standard tools to assess malingering ( $\mathrm{M}$ FAST) showed no evidence of malingering. To evaluate her case further, three of her identities were assessed using the MIPS: her PI, a $\mathrm{Tl}$, and an Al. Crucially, the three profiles were very different, with the largest differences observed between $\mathrm{PI}$ and $\mathrm{Tl}$; also, the three profiles scored high in Consistency, and moderate to low in Positive Impression and Negative Impression 
scales, thus indicating that the profiles were valid for interpretation. Interestingly, the $\mathrm{Pl}$ and the $\mathrm{Tl}$ exhibited very different (often opposite) personality styles, which may indicate opposing coping strategies. Together, the M-FAST and MIPS suggest absence of malingering.

The contribution of this case study is twofold: first, it suggests that using personality inventories that assess personality styles rather than psychopathological traits may be useful to assess the response consistency and positive/negative impression associated with each identity. Arguably, one should expect high consistency and a moderateto-low inclination to give a positive or negative impression between DID identities in a genuine patient. However, studies employing suitable sample sizes will be required to assess the MIPS' sensitivity to malingering. Secondly, profiling DID identities may help clinicians to better-understand each DID identity's adaptation style, thereby providing important insights about copying strategies that DID patients in their PI may need to develop. For example, we found many areas in which $\mathrm{Pl}$ and $\mathrm{TI}$ elevated opposite scales, thus exhibiting a possible compensation effect of the latter over the former. Arguably, Tls' personality styles might arise in opposition to $\mathrm{Pl}^{\prime}$ s styles to bring new coping strategies (46-49). Oftentimes, for example, Tls regard $\mathrm{PI}$ as useless and shy, stressing this contrast in adaptation. Future studies could employ personality-style inventories that go beyond psychopathological traits to enhance malingering evaluations and complement psychotherapeutic assessments.

\section{Acknowledgements}

This work was partially supported by a PhD studentship awarded by ANID/CONICYT at the University of Edinburgh and a postdoctoral fellowship awarded by Karolinska Institutet to the first author. The clinical work involved in this case study took place in Viña del Mar, Chile.

\section{Competing interests}

The authors declare no competing interests.

\section{Data availability statement}

The patient's raw data are subject to privacy restrictions and therefore cannot be shared.

\section{References}

1. Johnson JG, Cohen P, Kasen S, Brook JS. Dissociative disorders among adults in the community, impaired functioning, and axis I and II comorbidity. J Psychiatr Res. 2006;40(2):131-40.

2. Sar V. Epidemiology of Dissociative Disorders: An Overview. Epidemiol Res Int. 2011:e404538.

3. Putnam FW, Guroff JJ, Silberman EK, Barban L, Post RM. The clinical phenomenology of multiple personality disorder: review of 100 recent cases. J Clin Psychiatry. 1986;47(6):285-93.

4. van der Hart $\mathrm{O}$, Bolt $\mathrm{H}$, van der Kolk BA. Memory Fragmentation in Dissociative Identity Disorder. J Trauma Dissociation. 2005;6(1):5570.

5. Gleaves DH. The sociocognitive model of dissociative identity 
disorder: a reexamination of the evidence. Psychol Bull.

1996;120(1):42-59.

6. Gušić S, Cardeña E, Bengtsson H, Søndergaard HP. Adolescents' Dissociative Experiences: the Moderating Role of Type of Trauma and Attachment Style. J Child Adolesc Trauma. 2016;9(4):341-51.

7. Lewis DO, Yeager CA, Swica Y, Pincus JH, Lewis M. Objective Documentation of Child Abuse and Dissociation in 12 Murderers With Dissociative Identity Disorder. Am J Psychiatry. 1997;154(12):1703-10.

8. Brand BL, Webermann AR, Snyder $B L$, Kaliush PR. Detecting clinical and simulated dissociative identity disorder with the Test of Memory Malingering. Psychol Trauma Theory Res Pract Policy. 2019;11(5):513-20.

9. Pietkiewicz IJ, Bańbura-Nowak A, Tomalski R, Boon S. Revisiting FalsePositive and Imitated Dissociative Identity Disorder. Front Psychol. $2021 ; 12$.

10. Brown D, Scheflin AW. Factitious Disorders and Trauma-Related Diagnoses. J Psychiatry Law. 1999;27(3-4):373-422.

11. Allen JJ, Movius HL. The objective assessment of amnesia in dissociative identity disorder using event-related potentials. Int J Psychophysiol. 2000;38(1):21-41.

12. Huntjens RJC, Postma A, Hamaker EL, Woertman L, Van Der Hart O, Peters M. Perceptual and conceptual priming in patients with dissociative identity disorder. Mem Cognit. 2002;30(7):1033-43.

13. Huntjens RJC, Peters ML, Woertman $L$, van der Hart O, Postma A. Memory transfer for emotionally valenced words between identities in dissociative identity disorder. Behav Res Ther. 2007;45(4):775-89.

14. Nissen MJ, Ross JL, Willingham DB, Mackenzie TB, Schacter DL. Memory and awareness in a patient with multiple personality disorder. Brain Cogn. 1988;8(1):117-34.

15. Huntjens RJC, Postma A, Woertman $L$, van der Hart $O$, Peters ML.

Procedural memory in dissociative identity disorder: When can interidentity amnesia be truly established? Conscious Cogn. 2005;14(2):377-89.

16. Huntjens RJC, Postma A, Peters ML, Woertman $L$, van der Hart $O$. Interidentity amnesia for neutral, episodic information in dissociative identity disorder. J Abnorm Psychol. 2003;112(2):290-7.

17. Marsh RJ, Dorahy MJ, Verschuere B, Butler C, Middleton W, Huntjens RJC. Transfer of episodic selfreferential memory across amnesic identities in dissociative identity disorder using the Autobiographical Implicit Association Test. J Abnorm Psychol. 2018;127(8):751-7.

18. Huntjens RJC, Verschuere B, McNally RJ. Inter-Identity Autobiographical Amnesia in Patients with Dissociative Identity Disorder. PLOS ONE. 2012;7(7):e40580.

19. Huntjens RJC, Wessel I, Ostafin BD, Boelen PA, Behrens F, van Minnen A. Trauma-related self-defining memories and future goals in Dissociative Identity Disorder. Behav Res Ther. 2016;87:216-24.

20. Bryant RA. Autobiographical memory across personalities in dissociative identity disorder: a case report. J Abnorm Psychol. 1995;104(4):625-31. 
21. Dalenberg CJ, Brand BL, Gleaves DH, Dorahy MJ, Loewenstein RJ, Cardeña $E$, et al. Evaluation of the evidence for the trauma and fantasy models of dissociation. Psychol Bull. 2012;138(3):550-88.

22. Huntjens RJC, Wessel I, Hermans D, van Minnen A. Autobiographical memory specificity in dissociative identity disorder. J Abnorm Psychol. 2014;123(2):419-28.

23. Brand BL, McNary SW, Loewenstein RJ, Kolos AC, Barr SR. Assessment of genuine and simulated dissociative identity disorder on the structured interview of reported symptoms. J Trauma Dissociation. 2006;7(1):63-85.

24. Welburn KR, Fraser GA, Jordan SA, Cameron C, Webb LM, Raine D. Discriminating Dissociative Identity Disorder from Schizophrenia and Feigned Dissociation on Psychological Tests and Structured Interview. J Trauma Dissociation. 2003 1;4(2):109-30.

25. Brand BL, Chasson GS.

Distinguishing simulated from genuine dissociative identity disorder on the MMPI-2. Psychol Trauma Theory Res Pract Policy. 2015;7(1):93-101.

26. Brand BL, Chasson GS, Palermo CA, Donato FM, Rhodes KP, Voorhees EF. MMPI-2 Item Endorsements in Dissociative Identity Disorder vs. Simulators. J Am Acad Psychiatry Law. 2016;44(1):63-72.

27. Stadnik RD, Brand B, Savoca A. Personality assessment inventory profile and predictors of elevations among dissociative disorder patients. J Trauma Dissociation. 2013;14(5):546-61.

28. Rodewald F, Wilhelm-Göling C, Emrich HM, Reddemann L, Gast U.
Axis-I comorbidity in female patients with dissociative identity disorder and dissociative identity disorder not otherwise specified. J Nerv Ment Dis. 2011;199(2):122-31.

29. Rogers R, Gillard ND, Wooley CN, Ross CA. The detection of feigned disabilities: the effectiveness of the Personality Assessment Inventory in a traumatized inpatient sample. Assessment. 2012;19(1):77-88.

30. Lanfranco RC, Rivera-Rei Á, Huepe D, Ibáñez A, Canales-Johnson A. Beyond imagination: Hypnotic visual hallucination induces greater lateralised brain activity than visual mental imagery. Neurolmage. 2021;239:118282.

31. Lanfranco RC, Canales-Johnson A, Huepe D. Hypnoanalgesia and the study of pain experience: from Cajal to modern neuroscience. Front Psychol. 2014; 5: 1125.

32. Canales-Johnson A, Lanfranco R, Vargas E, Ibáñez A. Neurobiología de la hipnosis y su contribución a la comprensión de la cognición y la conciencia. An Psicol. 2012;28(3):1003-10.

33. Terhune DB, Cleeremans A, Raz A, Lynn SJ. Hypnosis and top-down regulation of consciousness. Neurosci Biobehav Rev. 2017;81:59-74.

34. Lanfranco RC, Adolfi F, Ibáñez A. Hypnotic suggestion: A test for the voluntary action problem. Cogn Neurosci. 2014;5(3-4):209-10.

35. Deeley Q. Chapter 47 - Hypnosis as therapy for functional neurologic disorders. In: Hallett M, Stone J, Carson A, editors. Handbook of Clinical Neurology. Elsevier; 2016. p. 585-95. (Functional Neurologic Disorders; vol. 139). 
36. Fine CG. Cognitive Behavioral Hypnotherapy for Dissociative Disorders. Am J Clin Hypn. 2012;54(4):331-52.

37. Kennerley H. Cognitive therapy of dissociative symptoms associated with trauma. Br J Clin Psychol. 1996;35(3):325-40.

38. Millon T. Disorders of Personality: DSM-IV and Beyond. 2nd edition. New York: Wiley; 1995.

39. Millon T. Millon Index of Personality Styles Revised. Minneapolis: Pearson; 2003.

40. Aparicio García ME, Sánchez López MP. Los estilos de personalidad: su medida a través del inventario Millon de estilos de personalidad. An Psicol. 1999;15(2):191-211.

41. Miller H. The Miller-Forensic Assessment of Symptoms Test (MFAST): Professional Manual [Internet]. Florida: Psychological Assessment Resources; 2001.

42. Miller HA. The Miller-Forensic Assessment of Symptoms Test (MFast): Test Generalizability and Utility Across Race, Literacy, and Clinical Opinion. Crim Justice Behav. 2005;32(6):591-611.

43. Lilienfeld SO, Lynn SJ, Kirsch I, Chaves JF, Sarbin TR, Ganaway GK, et al. Dissociative identity disorder and the sociocognitive model: recalling the lessons of the past. Psychol Bull. 1999;125(5):507-23.

44. Spanos NP. Multiple identity enactments and multiple personality disorder: a sociocognitive perspective. Psychol Bull. 1994;116(1):143-65.

45. Drob SL, Meehan KB, Waxman SE. Clinical and conceptual problems in the attribution of malingering in forensic evaluations. J Am Acad

Psychiatry Law. 2009;37(1):98-106.

46. Kluft RP. The phenomenology and treatment of extremely complex multiple personality disorder. Dissociation. 1988;1(4):47-58.

47. Kluft RP. Clinical presentations of multiple personality disorder. Psychiatr Clin North Am. 1991;14(3):605-29.

48. Kluft RP, Fine CG, editors. Clinical Perspectives on Multiple Personality Disorder. American Psychiatric Association Publishing; 1993.

49. Ozturk E, Sar V. Formation and Functions of Alter Personalities in Dissociative Identity Disorder: A Theoretical and Clinical Elaboration. J Psychol Clin Psychiatry. 2016;6(6). 